\title{
Target identification using drug affinity responsive target stability (DARTS)
}

\author{
Brett Lomenick ${ }^{1}$, Gwanghyun Jung ${ }^{1}$, James A. Wohlschlegel ${ }^{2,3}$, and Jing Huang ${ }^{1,3,{ }^{*}}$ \\ ${ }^{1}$ Department of Molecular and Medical Pharmacology, David Geffen School of Medicine, \\ University of California Los Angeles \\ 2Department of Biological Chemistry, David Geffen School of Medicine, University of California \\ Los Angeles
}

${ }^{3}$ Molecular Biology Institute, University of California Los Angeles

\begin{abstract}
Drug Affinity Responsive Target Stability is a general methodology for identifying and studying protein-ligand interactions. The technique is based on the principle that when a small molecule compound binds to a protein, the interaction stabilizes the target protein's structure such that it becomes protease resistant. DARTS is particularly useful for the initial identification of the protein targets of small molecules, but can also be used to validate potential protein-ligand interactions predicted or identified by other means and to estimate the affinity of interactions. The approach is simple and advantageous because it can be performed using crude cell lysates and other complex protein mixtures (without requiring purified proteins), and uses native, unmodified small molecules. The protocols provided in this article describe the general approach for performing DARTS experiments, which can be easily modified and scaled to fit the criteria and purpose of any individual project.
\end{abstract}

\section{Keywords}

Target ID; DARTS; Proteins; Ligands; Binding; Proteomics; Mass Spectrometry

\section{INTRODUCTION}

This article describes general procedures for performing Drug Affinity Responsive Target Stability (DARTS) assays to identify protein targets of small molecule ligands. The basis for DARTS is that a protein becomes stabilized upon binding to a small molecule compound or other ligand, which leads to decreased susceptibility of the target protein to degradation by proteases (Lomenick et al., 2009; Lomenick et al., 2011). This decreased proteolysis is specific to the target protein(s) and occurs for both high and low affinity compounds. Moreover, DARTS works especially well using extremely complex protein samples such as whole cell lysates where non-specific protein-ligand interactions are minimized due to the large number and variety of proteins in the mixture. DARTS is advantageous because any small molecule can be used in its native form, meaning no Structure-Activity Relationship (SAR) studies or chemical modifications to the ligand are necessary for target identification. In contrast, affinity chromatography and most other affinity-based methods for target ID

\footnotetext{
*jinghuang@mednet.ucla.edu.

Internet Resources

http://labs.pharmacology.ucla.edu/huanglab/DARTS_faq.html

DARTS Help Forum. This provides real time updated answers and discussions for the frequently asked questions from the community.
} 
require each ligand to be chemically modified, which presents a range of complications (see (Lomenick et al., 2011) for further discussion). In addition to de novo target identification, DARTS has also proven useful for validating binding of small molecules to proposed target proteins identified through other means (Aghajan et al., 2010; Chen et al., 2011).

\section{STRATEGIC PLANNING}

There are a few general key choices that must be made for each DARTS experiment, but overall the procedure is relatively standardized. First, the source of protein must be chosen. Generally any cell type that is sensitive to the biological effects of the small molecule can be used. We have successfully performed DARTS with lysates from a range of mammalian cells, including HEK293, HeLa, Jurkat, A549, MEFs, and Raw264.7, as well as from the yeast $S$. cerevisiae. Second, any small molecule believed to bind proteins should be suitable for DARTS (including drug-like small molecules that are not susceptible to proteolysis, and peptide ligands that are themselves susceptible to proteolysis but whose binding to target proteins would protect them from proteolysis), but the concentration range of small molecule to use is also an important consideration. Given that the targets of most small molecules being used for DARTS are unknown, the binding affinities will also not be known. Therefore, one can only estimate the binding affinity to the most relevant target(s) based upon the $\mathrm{EC}_{50}$ of the compound, although this correlation may not be valid for all compounds and biological systems. Since the $\mathrm{EC}_{50}$ gives only a rough estimate of binding affinity, we suggest initially using a concentration of the compound that is 10 -fold higher than the $\mathrm{EC}_{50}$. Using a concentration of compound that is significantly higher than the $\mathrm{K}_{\mathrm{D}}$ will help ensure maximal protection of the target protein from proteolysis by saturating the protein with ligand.

There are many different proteases available that could be used with DARTS. We have primarily used only two: thermolysin and Pronase. Thermolysin is a metalloendopeptidase from a thermophilic bacterium with low cleavage specificity. Its primary attribute is that it can only efficiently digest proteins that are unfolded (Arnold et al., 1996). Pronase, on the other hand, is a mixture of multiple proteases that can digest both folded and unfolded proteins. For proteins that can be digested by thermolysin under standard conditions, the magnitude of protection from proteolysis afforded by small molecule ligands is typically high. However, if the target protein is unable to be digested with thermolysin (e.g., GAPDH), then Pronase must be used. When DARTS is used as a tool for novel target identification, Pronase is the preferred enzyme choice given the limited substrate pool of thermolysin.

In order to identify novel targets of small molecules by DARTS, one or more proteomics techniques must be used subsequent to the proteolysis. In our initial DARTS study, we used the simplest method possible, SDS-PAGE and gel staining, in order to identify the known target of didemnin B and a novel target of resveratrol (Lomenick et al., 2009). However, the majority of proteins in most cells and tissues are not present in high abundance and cannot be observed using unbiased gel-based proteomics. Therefore, more sensitive, quantitative proteomics technologies must be employed (see (Lomenick et al., 2011) for a complete discussion). Our lab is currently combining many of the newest and most sensitive proteomics methods available with DARTS in order to identify the less abundant protein targets of small molecules. For the purpose of this protocol, we are focusing on providing as much information as possible for performing the initial part of a DARTS experiment. It will be up to each individual investigator to determine which proteomics method to use in conjunction with DARTS, which includes but is not limited to Western blotting, SDSPAGE, 2D-PAGE, and gel-free MS-based proteomics (see (Lomenick et al., 2011) and Support Protocols 1 and 2 for further discussion). 


\section{BASIC PROTOCOL 1 \\ DARTS EXPERIMENT FOR ANALYZING DRUG BINDING TO PROTEIN TARGETS IN MAMMALIAN CELL LYSATES WITH PRONASE}

Once the details of cell type and ligand concentration are decided, the basic protocol provided here can be used in conjunction with any quantitative analytical platform (such as Western blotting and gel-based or gel-free MS-based proteomics). The amounts of reagents used in this procedure are optimized for performing DARTS with the purpose of analyzing the results by Western blotting or SDS-PAGE and gel staining, but can easily be scaled up or down as necessary (see SUPPORT PROTOCOL 2 for gel-free proteomics). In this procedure you will collect and lyse cells, prepare and quantify the lysates, treat with the ligand/compound of interest and a negative control (e.g., solvent or inactive analog), and perform the proteolysis (An overview is provided in Fig. 1). When looking at specific proteins by Western blotting, we advise initially using a range of Pronase concentrations to find the optimal amount needed to partially digest the proteins of interest. Based on our observations that nearly all proteins will be partially to completely digested within the range of 1:100 to 1:10,000 Pronase to protein ratio (a 1:100 ratio will use $1 \mu \mathrm{g}$ Pronase for every $100 \mu \mathrm{g}$ protein), we begin by digesting aliquots of the samples with 1:100, 1:300, 1:1000, 1:3000, and 1:10,000 ratios. Here we use the mass ratio of Pronase to protein since protein mass directly correlates with the number of peptide bonds, which are the actual substrate of proteases. Once the optimal amount of Pronase is determined for a protein of interest (one in which approximately $50-80 \%$ of the protein is digested), subsequent experiments to perform concentration-effect curves (or time courses) or to test multiple small molecules can be done using this single Pronase concentration. On the other hand, when mass spectrometry identification will be used to look for unknown protein targets, we typically achieve the best results with high concentrations of Pronase between 1:1000 and 1:100. Lower amounts of Pronase result in too many proteins not being digested at all, which limits the effectiveness of the gel-based or gel-free proteomics approaches. Furthermore, we have found that we can detect significant amounts of specific proteins using mass spectrometry in proteolysed samples even when the protein can no longer be detected by Western blotting. We believe this is due to the fact that the proteins have been cut into multiple small peptides that are no longer efficiently recognized by antibodies, although other explanations may exist.

\section{Materials}

M-PER lysis buffer (Pierce cat. no. 78501)

$20 \times$ Protease inhibitor solution (see recipe)

Phosphatase inhibitor solutions (100 mM $\beta$-pyrophosphate, $50 \mathrm{mM}$ Sodium

Pyrophosphate, $200 \mathrm{mM}$ Sodium Vanadate, and 1 M Sodium Fluoride)

Cell culture in logarithmic growth phase (up to $70-80 \%$ confluent)

Phosphate Buffered Saline (PBS)

Cell scraper (such as Fisher cat. no. 08-100-241)

Refrigerated centrifuge capable of 18,000 rcf (such as Beckman Microfuge 22R)

$10 \times$ TNC Buffer (see recipe)

BCA Protein Concentration Assay (Pierce cat. no. 23225 or similar assay)

$100 \times$ stock solution of small molecule(s) in DMSO (DMSO can be replaced with other vehicle of choice)

DMSO (or other corresponding vehicle) 
Pronase stock solution (see recipe)

$1 \times$ TNC Buffer (dilute 10× TNC Buffer 10-fold in $\mathrm{dH}_{2} \mathrm{O}$ )

\section{Collect and Lyse Cells}

1. Prepare $1 \mathrm{~mL}$ of M-PER lysis buffer by mixing $883 \mu \mathrm{L}$ M-PER, $10 \mu \mathrm{L} 100 \mathrm{mM} \beta$ pyrophosphate, $50 \mu \mathrm{L} 50 \mathrm{mM}$ Sodium Pyrophosphate, $5 \mu \mathrm{L} 200 \mathrm{mM}$ Sodium Vanadate, $2 \mu \mathrm{L} 1 \mathrm{M}$ Sodium Fluoride, and $50 \mu \mathrm{L} 20 \times$ Protease inhibitor solution on ice.

For DARTS experiments with mammalian cells we typically lyse using the commercial M-PER buffer, which has worked well for a variety of cell lines and small molecule-protein pairs. However, it is not necessary to use M-PER, as DARTS can be successfully performed with a variety of gentle, non-denaturing lysis buffers (e.g. 0.2 - 1\% Triton X-100, NP-40). However, harsh, denaturing lysis buffers like RIPA (radio-immunoprecipitation assay) buffer should be avoided for DARTS, as most proteins must retain their native complexes and/or structures in order to bind ligands. The exact protease and phosphatase inhibitors used are also not typically critical, and multiple companies sell inhibitor cocktails that are similar in composition and could be used instead of the individual ones listed here. These inhibitors will not significantly affect Pronase (nor thermolysin or subtilisin), which are added in excess during the ensuing DARTS reactions. Whether or not adding phosphatase inhibitors is crucial for DARTS has not been tested.

2. Remove the growth medium from a single $10 \mathrm{~cm}$ dish of cells and wash the cells once with $1 \mathrm{~mL}$ cold PBS.

If cells that grow in suspension will be used, simply pellet the cells by centrifuging at $1000 \mathrm{rcf}$ for $10 \mathrm{~min}$ at $4^{\circ} \mathrm{C}$. After centrifuging, remove the growth medium, resuspend the cells in M-PER lysis buffer, and then proceed to step 4 of this protocol. For Jurkat cells, $3 \times 10^{7}$ cells lysed in $600 \mu \mathrm{L}$ M-PER will typically yield soluble lysates of approximately $5 \mu \mathrm{g}$ protein $/ \mu \mathrm{L}$.

3. Apply $600 \mu \mathrm{L}$ cold M-PER lysis buffer (with added protease and phosphatase inhibitors) onto the cells and collect the cells with a cell scraper (by holding the plate at an angle and gently scraping from top to bottom).

4. Transfer the M-PER/lysing cells into a $1.5 \mathrm{~mL}$ tube pre-chilled on ice, mix it well by pipetting up and down several times, and incubate the tube on ice for $10 \mathrm{~min}$.

Upon completion of the incubation the cells will be completely lysed open and soluble proteins will be extracted into the M-PER solution. You should notice a white, cloudy material floating within the solution, which is primarily DNA. This material must first be separated from the soluble proteins before performing DARTS.

\section{Prepare Cell Lysates for DARTS Experiment}

5 Centrifuge the tube at $18,000 \times g$ for $10 \mathrm{~min}$ at $4^{\circ} \mathrm{C}$, best in a refrigerated centrifuge (e.g., Beckman Coulter Microfuge 22R).

6 Transfer $600 \mu \mathrm{L}$ of the supernatant into a new $1.5 \mathrm{~mL}$ tube and discard the pellet. 
The pellet contains the DNA and some other insoluble materials from the cell. The supernatant contains the soluble proteins from the cytoplasm, nucleus, mitochondria, and other cellular compartments.

Add $66.7 \mu \mathrm{L} \mathrm{10 \times} \mathrm{TNC} \mathrm{Buffer} \mathrm{to} \mathrm{the} \mathrm{protein} \mathrm{lysates} \mathrm{and} \mathrm{mix} \mathrm{well.}$

DARTS with Pronase works with or without adding the TNC buffer (although we have not done a side-by-side comparison). In our earlier DARTS experiments with thermolysin the TNC buffer was added to ensure that there was enough $\mathrm{Ca}^{2+}$ for thermolysin to be fully active, given that the exact composition of M-PER is unknown and that most common lysis buffers do not contain $\mathrm{Ca}^{2+}$.

8 Measure the protein concentration of the lysates using the BCA, Bradford or other assay, according to the manufacturer's instructions.

We routinely use the BCA protein concentration assay, which is not affected by the M-PER or TNC buffers. The exact protein concentration is not critical, but DARTS may not work as well if the protein is too dilute. We find that an optimal protein concentration for DARTS may be between $4-6 \mu \mathrm{g} / \mu \mathrm{L}$, though we have also used $2 \mu \mathrm{g} /$ $\mu \mathrm{L}$ with good results (lower has not been tested extensively). The amount of lysis buffer and cells used in this protocol should result in lysates of approximately $5 \mu \mathrm{g} / \mu \mathrm{L}$.

Although the exact protein concentration does not appear to be critical, the use of a fixed protein concentration in this protocol is primarily to standardize the protease amount. We initially optimized the amount of proteolysis for specific proteins (wherein 50-80\% of the protein of interest is digested, see above) based on the ratio of protease to protein. However, the amount of proteolysis in a sample depends on a multitude of factors, including the concentration of the protein sample, the concentration of the protease, the buffer components, and the time of proteolysis. Therefore, two samples with different protein concentrations but digested with the same protease:protein ratio will not be digested equally because both the protein and the protease concentrations will be different.

9 Split the lysates into two samples by transferring $297 \mu \mathrm{L}$ into each of two 1.5 mL tubes.

At this point the lysates should be allowed to warm to room temperature. Some small molecules may have low solubility in aqueous solution and will be more prone to precipitate at lower temperatures. Moreover, hydrophobic interactions are destabilized at low temperatures, and binding kinetics should be faster at the higher temperature. The rest of the experiment could also be performed at physiological temperature, but this is not necessary.

\section{Incubate protein lysates with the small molecule}

10 Add into one tube $3 \mu \mathrm{L}$ DMSO, and into the other tube $3 \mu \mathrm{L}$ small molecule at $100 \times$ the final concentration for a 1:100 dilution.

The small molecule should be dissolved in 100\% DMSO. If another solvent must be used, such as ethanol, then substitute this solvent for DMSO in this step. Alternatively, if an inactive analog of the small 
molecule is available, it could be used as the control. The small molecule stock solution does not have to be exactly $100 \times$, but we advise that the final DMSO concentration in the lysates be kept low, around $1-2 \%$, as higher concentrations may interfere with binding and proteolysis. We also prefer to not pipet volumes less than $1 \mu \mathrm{L}$, as the chance of significant pipetting error becomes greater. Therefore, do not use a small molecule stock solution that is greater than $300 \times$ directly (dilute it first), unless the volume of lysates is also larger.

11 Mix the samples immediately by gently flicking the tubes with your finger several times, spin the tubes briefly in a microfuge to bring all the liquid to the bottom of the tubes, and allow them to incubate at room temperature for $1 \mathrm{hr}$ (or longer if determined necessary from pilot studies).

It is critical that you mix the samples thoroughly but gently, to ensure that the small molecule/protein solution becomes homogeneous and binding equilibrium is reached. Furthermore, it is essential that you do not vortex or use any other harsh mixing method on any sample that contains protein! This will cause many proteins to become denatured and/or aggregated.

\section{Preparation for proteolysis}

12 Thaw one aliquot of $10 \mathrm{mg} / \mathrm{mL}$ Pronase quickly and place on ice.

13 Dilute Pronase to $1.25 \mathrm{mg} / \mathrm{mL}$ by mixing $12.5 \mu \mathrm{L}$ Pronase with $87.5 \mu \mathrm{L}$ cold $1 \times$ TNC Buffer, which will serve as the 1:100 Pronase stock solution.

It is essential to keep all protease solutions on ice at all times to prevent them from starting to digest themselves. The $1.25 \mathrm{mg} / \mathrm{mL}$ Pronase solution will be the highest concentration used in this experiment. The Pronase stock solutions prepared in this and the following step are calculated for lysates of $5 \mu \mathrm{g}$ protein/ $\mu \mathrm{L}$, and will need to be modified if the protein concentration is significantly different.

14 Dilute the 1:100 Pronase solution serially by mixing with $1 \mathrm{X}$ TNC to create 1:300, 1:1000, 1:3000 and 1:10000 Pronase stock solutions.

\section{Perform proteolysis}

15 Prepare 5 aliquots from both protein samples, each with $50 \mu \mathrm{L}$, and save the remaining $50 \mu \mathrm{L}$ of each sample as a non-digested control sample.

One aliquot of the compound-treated sample and one of the DMSO control sample will be digested with each of the five Pronase stock solutions.

16 Start a timer and immediately add $2 \mu \mathrm{L}$ 1:100 Pronase solution to one aliquot of compound-treated sample, mix well, and incubate at room temperature.

17 At exactly 1 min after starting the first digest, add $2 \mu \mathrm{L}$ 1:100 Pronase solution to one aliquot of the DMSO sample, mix well, and incubate at room temperature.

18 Continue to begin digests of the 8 remaining aliquots in 1-min intervals by adding $2 \mu \mathrm{L}$ of the corresponding Pronase stock solution into an aliquot of each protein sample. 
19 After 30 min stop the digestion of the first aliquot began by adding $3 \mu \mathrm{L}$ cold $20 \times$ Protease inhibitor solution, mixing well, and placing on ice.

Alternatively, if the samples will be run on SDS-PAGE gels, the digestions can be stopped by directly adding SDS loading buffer into each sample and heating to $70^{\circ} \mathrm{C}$ for $10 \mathrm{~min}$ or $95^{\circ} \mathrm{C}$ for $5 \mathrm{~min}$ immediately, without needing to add protease inhibitors. After heating, the samples may be loaded onto gels right away or stored at $-20^{\circ} \mathrm{C}$.

20 Stop all the remaining digestions in the order they were started in 1-min intervals by adding $3 \mu \mathrm{L}$ cold $20 \times$ Protease inhibitor solution to each (or SDS loading buffer and heating as above immediately), mixing well, and placing on ice.

After stopping the proteolysis, the DARTS experiment is finished. Now the samples can be analyzed by SDS-PAGE or Western blotting, using any standard equipment and reagents available. When performing Western blotting to identify differentially proteolysed target proteins, it is critical to blot for additional control proteins to ensure that the differential proteolysis is not widespread, as would occur if the drug used affects the activity of the DARTS protease(s). We routinely blot for GAPDH, actin, and tubulin as control proteins, but other proteins could also be used. It is important to not be reliant on just one control protein, especially as these proteins are known targets of a variety of small molecule compounds.

\section{BASIC PROTOCOL 2}

\section{THERMOLYSIN DIGESTION DARTS EXPERIMENT FOR ANALYZING BINDING OF SMALL MOLECULES TO PROTEIN TARGETS IN YEAST CELL LYSATES}

For the same reason that yeast has been a favored organism for genetics/genomics-based target ID approaches (reviewed in (Lomenick et al., 2009)), the smaller size and lesser complexity of the yeast proteome (e.g., compared to the human proteome) means that $d e$ novo DARTS target ID using yeast cell lysates is also likely advantageous - when the target of your small molecule is conserved in yeast. However, unlike phenotype-based target ID, DARTS may still be useful even when there is no conserved yeast target; for instance, because DARTS can detect very low affinity (mid to high-micromolar) binding interactions, a non-optimal binding target identified in yeast could give clues to homologous mammalian target proteins or domains that may be higher affinity targets.

This alternative protocol will provide instructions for performing DARTS using $S$. cerevisiae cell lysates and the alternative protease thermolysin. Most of the protocol is very similar to Basic Protocol 1, with the main difference being yeast cells require different lysis conditions due to their cell wall. Both Pronase and thermolysin can be used with lysates from any cell type, but typically much higher amounts of thermolysin are required to achieve significant digestion of the proteome. Despite the limited digestive capabilities of thermolysin, as discussed above, it still proves useful for some proteins. This protocol, like the first one, can be scaled up or down as necessary. The volumes of reagents given provide sufficient protein for Western blotting and SDS-PAGE. Although high concentrations of thermolysin are required to see significant digestion on stained gels, some individual proteins are still quite sensitive to its proteolysis activity. Therefore, this protocol provides instructions for digesting with thermolysin to protein ratios of 1:10, 1:50, 1:250, 1:1250, and 1:6250. If the DARTS experiment will be analyzed using proteomics methods such as gel staining or MudPIT, the lower amounts of thermolysin may be omitted since most proteins 
will not be digested. However, we recommend using the lower amounts of thermolysin when initially performing Western blotting in order to not over-digest target proteins.

DARTS-Western analysis in yeast is largely facilitated by the availability of genome-wide yeast epitope-tagged collections. We have made use of the commercialized library of TAPtagged strains (Ghaemmaghami et al., 2003) in many of our DARTS experiments ((Lomenick et al., 2009), and unpublished), and the HA-tagged and GST-tagged strains may also be useful for this purpose (Ross-Macdonald et al., 1999; Martzen et al., 1999; Zhu et al., 2001).

\section{Materials}

$2 \times$ Triton X-100 lysis buffer (see recipe)

$20 \times$ Protease inhibitor solution: (see recipe)

$4 \times$ Phosphatase inhibitor solution (see recipe)

Wildtype strain of S. cerevisiae grown to mid-log phase $\left(\sim 2 \times 10^{7}\right.$ cells $\left./ \mathrm{mL}\right)$

Refrigerated centrifuge capable of 18,000 rcf (such as Beckman Microfuge 22R)

$0.5 \mathrm{~mm}$ glass beads (such as BioSpec Products cat. no. 11079105)

21 Gauge needle

Benchtop microfuge

$1 \times$ TNC Buffer (diluted from 10× TNC Buffer)

BCA Protein Concentration Assay (Pierce cat. no. 23225 or similar assay)

100x small molecule stock solution in DMSO

DMSO

Thermolysin stock solution (see recipe)

0.5 M EDTA (pH 8.0)

\section{Collect and Lyse Cells}

1. Prepare $300 \mu \mathrm{L}$ Triton $\mathrm{X}-100$ lysis buffer by mixing on ice $60 \mu \mathrm{L} \mathrm{dH_{2 }} \mathrm{O}, 150 \mu \mathrm{L} 2 \times$ Triton X-100 lysis buffer, $75 \mu \mathrm{L} 4 \times$ Phosphatase inhibitor solution, and $15 \mu \mathrm{L} 20 \times$ Protease inhibitor solution.

2. Collect $25 \mathrm{~mL}$ yeast cells grown to mid-log phase $\left(\sim 2 \times 10^{7}\right.$ cells $\left./ \mathrm{mL}\right)$ by centrifuging at $1,000 \times \mathrm{g}$ for $5 \mathrm{~min}$.

3. Remove the medium completely and put the cell pellet on ice.

4. Resuspend the cells in $300 \mu \mathrm{L}$ cold Triton $\mathrm{X}-100$ lysis buffer and transfer into a 1.5 $\mathrm{mL}$ tube containing approximately $600 \mu \mathrm{L} 0.5 \mathrm{~mm}$ glass beads.

5. Vortex the tube of cells at highest speed for $1 \mathrm{~min}$ at room temperature.

6. Transfer the tube of cells to ice and allow them to rest for $1 \mathrm{~min}$ on ice.

7. Repeat this cycle of 1 min vortexing and 1 min resting 4 times.

8. Invert the tube and poke a single hole in the bottom using a 21 Gauge needle, then place the tube into another $1.5 \mathrm{~mL}$ tube and centrifuge for 15 seconds at $3000 \mathrm{rpm}$ in a standard benchtop microfuge to separate the lysates from the beads. 
The $0.5 \mathrm{~mm}$ glass beads will remain in the original tube and can be discarded.

\section{Prepare Cell Lysates for DARTS Experiment}

9 Centrifuge the new tube with the lysates at $18,000 \times g$ (or full speed) for $10 \mathrm{~min}$ at $4^{\circ} \mathrm{C}$.

10 Transfer the supernatant to a new tube on ice and discard the pellet.

The pellet contains the DNA and other insoluble materials from the cell, while most soluble proteins will be in the supernatant.

11 Measure the protein concentration of the lysates using the BCA or similar assay.

The amount of cells and lysis buffer used should yield around $10 \mathrm{mg} /$ ml protein.

12 Dilute lysates to $5 \mathrm{mg} / \mathrm{mL}$ by mixing $300 \mu \mathrm{L}$ lysates with $300 \mu \mathrm{L} 1 \times \mathrm{TNC}$ buffer.

\section{Incubate protein lysates with the drug}

13 Aliquot $297 \mu \mathrm{L}$ lysates into two different tubes.

14 Add $3 \mu \mathrm{L}$ DMSO into one tube and $3 \mu \mathrm{L} 100 \times$ compound into the other, mix them well, and incubate at room temperature.

\section{Preparation for proteolysis}

15 Unthaw one aliquot of $10 \mathrm{mg} / \mathrm{mL}$ thermolysin and place on ice immediately.

16 Dilute the $10 \mathrm{mg} / \mathrm{mL}$ thermolysin serially by mixing with $1 \mathrm{X}$ TNC to create 2 $\mathrm{mg} / \mathrm{mL}, 0.4 \mathrm{mg} / \mathrm{mL}, 80 \mu \mathrm{g} / \mathrm{mL}$, and $16 \mu \mathrm{g} / \mathrm{mL}$ thermolysin stock solutions.

The final ratios of the thermolysin solutions will be 1:50, 1:250, 1:1250, and 1:6250, along with the original $10 \mathrm{mg} / \mathrm{mL}$ solution for $1: 10$.

17 Prepare 5 aliquots from both protein samples, each with $50 \mu \mathrm{L}$, and save the remaining $50 \mu \mathrm{L}$ of each sample as a non-digested control sample.

One aliquot of the compound-treated sample and one of the DMSO control sample will be digested with each of the five thermolysin stock solutions.

\section{Perform proteolysis}

18 Start a timer and immediately add $2.5 \mu \mathrm{L} 10 \mathrm{mg} / \mathrm{mL}$ thermolysin solution to one aliquot of compound-treated sample, mix well, and incubate at room temperature.

19 At exactly $1 \mathrm{~min}$ after starting the first digest, add $2.5 \mu \mathrm{L} 10 \mathrm{mg} / \mathrm{mL}$ thermolysin solution to one aliquot of the DMSO sample, mix well, and incubate at room temperature.

20 Continue to begin digests of the 8 remaining aliquots in 1-min intervals by adding $2.5 \mu \mathrm{L}$ of the corresponding thermolysin solution into an aliquot of each protein sample.

21 After $15 \mathrm{~min}$, stop the digestion of the first aliquot began by adding $5 \mu \mathrm{L} 0.5 \mathrm{M}$ EDTA, mixing well, and placing on ice. 
22 Stop all the remaining digestions in the order they were started in 1-min intervals by adding $5 \mu \mathrm{L} 0.5 \mathrm{M}$ EDTA to each, mixing well, and placing on ice.

\section{SUPPORT PROTOCOL 1}

\section{PREPARATION OF DARTS SAMPLES FOR MUDPIT ANALYSIS}

The following is a general protocol for preparing DARTS samples for analysis by shotgun mass spectrometry, as recently described (Lomenick et al., 2011); filtering away small digested peptides from DARTS samples is not necessary for most other analyses, such as SDS-PAGE, Western blotting, or gel-free fractionation (support protocol 2).

DARTS should be performed as described in the Basic Protocols first, and then the samples processed using this protocol prior to MudPIT analysis (Washburn et al., 2001; Wolters et al., 2001). The purpose of this procedure is to filter away the small peptides generated by the DARTS proteolysis so that the sample only contains whole proteins and large protein fragments (those of $10 \mathrm{kDa}$ or larger). The filtered protein sample can then be analyzed by shotgun mass spectrometry (MudPIT) to identify protein targets. Dialysis of the DARTS samples can be performed instead of filtration, but this requires much longer time (overnight) and both procedures give similar results.

\section{Additional Materials}

Vivacon 500 10K MWCO Spin Columns (Sartorius Stedim cat. no. VN01H01)

TE Buffer

100\% (w/v) Trichloroacetic acid (TCA) (Sigma cat. no. T0699)

HPLC grade Acetone (Fisher cat. no. AC26831)

$8 \mathrm{M}$ urea, $100 \mathrm{mM}$ Tris- $\mathrm{HCl} \mathrm{pH} 8.5$ (prepared fresh)

$200 \mathrm{mM}$ Tris(2-carboxylethyl)-phosphine hydrochloride (TCEP)

$500 \mathrm{mM}$ Iodoacetamide (prepared fresh)

Sequencing-grade endoproteinase Lys-C

$100 \mathrm{mM}$ Tris $\mathrm{pH} 8.5$

$100 \mathrm{mM} \mathrm{CaCl} 2$

Sequencing-grade trypsin

90\% formic acid (HPLC grade, such as Fisher cat. no. PI-28905 diluted with HPLC grade water to $90 \%$ final concentration)

1. Perform DARTS for the compound of interest using Pronase ratios of $1: 300$ and 1:100 and/or a thermolysin ratio of 1:10, as described in Basic Protocols 1 and 2.

Other protease amounts may be tried, but lower protease amounts are unlikely to provide sufficient digestion of most proteins. On the other hand, higher amounts of protease or longer digestion times may allow for the identification of target proteins that are especially stable and resistant to proteolysis.

\section{Filter away digested peptides}

$2 \quad$ Add $400 \mu \mathrm{L}$ cold TE buffer into one Vivacon 500 10K spin column per sample. 
For the Pronase-digested samples you should include protease inhibitors in the TE Buffer, but this is not necessary for thermolysindigested samples.

3 Load $100 \mu \mathrm{g}$ protein per DARTS sample into each Vivacon column.

If SILAC or another stable isotope labeling method will be used for quantitative comparison, combine $50 \mu \mathrm{g}$ labeled protein from the compound-treated sample and $50 \mu \mathrm{g}$ labeled protein from the control sample into one Vivacon column and process together.

4 Centrifuge the columns at $12,000 \times g$ at $4^{\circ} \mathrm{C}$ until only about $20 \mu \mathrm{L}$ remains in the top of the column.

Try not to spin the columns dry, as protein recovery may be affected due to precipitation and protein sticking to the membrane. If the column is spun dry, resuspend the protein in TE buffer by pipetting up and down several times.

5 Discard the flow through, add $400 \mu \mathrm{L}$ cold TE buffer, and repeat the spin.

6 Repeat step 5 once more.

7 Collect the washed samples from the top of the filter columns and transfer to new tubes.

$8 \quad$ Wash the top of the filter columns with $30 \mu \mathrm{L}$ cold TE buffer to recover any remaining protein and combine this with the rest of each sample.

\section{Precipitate the protein samples}

9 Add $100 \%$ TCA to a final concentration of $20 \%$ and mix.

10 Incubate the samples on ice for at least 30 minutes (can be overnight).

11 Centrifuge the samples at $18,000 \mathrm{x}$ g for 15 minutes at $4^{\circ} \mathrm{C}$.

12 Remove the supernatant without disturbing the white protein pellet.

The pellet contains all the protein from the sample. You may leave a few microliters of the supernatant if necessary to avoid disturbing the pellet.

13 Wash the pellet with $500 \mu \mathrm{L}$ ice-cold Acetone.

14 Centrifuge the samples at $18,000 \times \mathrm{g}$ for 15 minutes at $4^{\circ} \mathrm{C}$.

15 Remove the supernatant as above without disturbing the protein pellet.

16 Repeat steps 13-15 once more for a second wash.

17 Allow the samples to air-dry by placing into a chemical hood for several minutes with the lids open until all the remaining acetone has evaporated.

At this point the protein pellet can be safely stored at $-20^{\circ} \mathrm{C}$ for longterm with the tube parafilmed, if necessary.

\section{Prepare the protein pellets for Lys-C/Trypsin digestion}

18 Dissolve each pellet in $50 \mu \mathrm{L} 8 \mathrm{M}$ urea, $100 \mathrm{mM}$ Tris-HCl pH 8.5.

$19 \mathrm{dd} 1.25 \mu \mathrm{L} 200 \mathrm{mM}$ TCEP to a final concentration of $5 \mathrm{mM}$.

20 Mix and incubate the sample at room temperature for 20 minutes. 
21 Add $1 \mu \mathrm{L} 500 \mathrm{mM}$ Iodoacetamide to a final concentration of $10 \mathrm{mM}$.

22 Mix and incubate the sample at room temperature for 20 minutes in the dark.

\section{Digest the samples with Lys-C and Trypsin}

23 Add $1 \mu \mathrm{g}$ Lys-C into the sample and incubate at $37^{\circ} \mathrm{C}$ for 4 hours in the dark.

24 Add $150 \mu \mathrm{L}$ of $100 \mathrm{mM}$ Tris $\mathrm{pH} 8.5$ for a final volume of $200 \mu \mathrm{L}$ and a final urea concentration of $2 \mathrm{M}$.

25 Add $2 \mu \mathrm{L} 100 \mathrm{mM} \mathrm{CaCl}_{2}$ for a final concentration of $1 \mathrm{mM}$.

26 Add $2 \mu \mathrm{g}$ trypsin and incubate at $37^{\circ} \mathrm{C}$ for at least 4 hours in the dark.

This step can be performed overnight.

27 Stop the digestion by adding $11.5 \mu \mathrm{L} 90 \%$ formic acid for a final concentration of $5 \%$.

The sample can be stored at $-80^{\circ} \mathrm{C}$ long-term. For additional information concerning preparing protein samples for mass

spectrometry, see Current Protocols in Protein Science Unit 23.6.

\section{MudPIT Analysis}

28 Analyze the samples by MudPIT. For additional details, see Current Protocols in Protein Science Unit 23.1.

\section{SUPPORT PROTOCOL 2}

\section{ANALYSIS OF DARTS SAMPLES BY IN-SOLUTION MOLECULAR WEIGHT-BASED FRACTIONATION AND MASS SPECTROMETRY}

In addition to the shotgun approach to DARTS described in SUPPORT PROTOCOL 1, molecular weight-based fractionation of DARTS samples, followed by mass spectrometry analysis of the fractions, has proven to be an even more powerful approach. In order for the shotgun approach to identify a target protein, a significant fraction of the protein must be completely digested into pieces small enough to be filtered away, resulting in an overall enrichment of the protein level in the compound-treated sample versus the control sample (Fig. 2, Scenario A). However, in many DARTS experiments the target protein is only partially digested, in which case protein fragments that are too large to be filtered away remain in the sample after proteolysis (Fig. 2, Scenario B; also see Fig. 3). Although the target protein is protected from proteolysis (indicated by the depletion of the full length protein in the control sample relative to the compound-treated sample), the total amount of the protein remains unchanged. In this scenario (B), it would be more difficult to identify the target protein using the "whole-sample" shotgun approach since that would require the identification and quantification of the small number of peptides derived from the proteolytically protected fragment in the background of all of the peptides from the entire protein.

To avoid failing to identify target proteins in such cases of partial proteolysis (false negatives), we hypothesized that a proteomics approach that analyzes the size of the proteins in addition to the amount present in a sample would be better able to identify target proteins with DARTS. We therefore implemented an in-solution molecular weight-based fractionation system called Gelfree (Protein Discovery, Inc.) that allows for precise separation of complex protein mixtures into multiple fractions of discrete molecular weight ranges. Combining the fractionation approach with DARTS and mass spectrometry analysis allows for the identification of proteins that have been proteolysed to a different extent 
between samples, even when the total amount of protein in the sample remains unchanged (Fig. 2, bottom row). This support protocol provides instructions for preparing DARTS samples for Gelfree fractionation.

\section{Additional Materials}

$1 \mathrm{M}$ dithiothreitol (DTT)

Zeba Spin Desalting Columns, 7K MWCO, $0.5 \mathrm{ml}$ (Thermo Scientific cat. no. 89882)

Gelfree 8100 Fractionation Station (Protein Discovery)

10\% Tris-Acetate Cartridge Kit (Protein Discovery cat. no. 42105)

1. Perform DARTS for the small molecule of interest using Pronase:protein ratios of $1: 300$ and $1: 100$.

2. Desalt $200 \mu \mathrm{g}$ aliquots from each DARTS sample with Zeba Spin Desalting Columns according to the directions provided by Thermo Scientific.

If SILAC or another stable isotope labeling method will be used for quantitative comparison, combine $100 \mu \mathrm{g}$ labeled protein from the compound-treated sample and $100 \mu \mathrm{g}$ labeled protein from the control sample into one and process as a single sample throughout this protocol.

3. Prepare the samples for fractionation by bringing their total volumes up to $112 \mu \mathrm{L}$ with $\mathrm{dH}_{2} \mathrm{O}$, adding $8 \mu \mathrm{L} 1 \mathrm{M}$ DTT and $30 \mu \mathrm{L} 5 \times$ sample buffer (provided in cartridge kit), mixing, and heating to $50^{\circ} \mathrm{C}$ for $10 \mathrm{~min}$.

4. Allow the samples to cool to room temperature and load each one into an individual lane of a $10 \%$ Tris-Acetate cartridge.

5. Separate the samples into a desired number of fractions according to the instructions provided by Protein Discovery.

The Gelfree system allows complete user control over how many fractions can be collected and to what molecular weight ranges those fractions correspond. We recommend initially using the general fractionation method provided with the cartridge kit, which will yield 12 evenly spread fractions of proteins ranging in size from about 5 to $100 \mathrm{kDa}$. If desired, variations from this method can be tested on a single DARTS sample and the fractions analyzed by traditional SDS-PAGE and silver staining to determine suitability prior to mass spectrometry analysis.

6. Prepare the fractions for mass spectrometry analysis by alkylation and trypsin digestion using the Filter-Aided Sample Preparation (FASP) protocol (Wisniewski et al., 2009).

FASP is recommended because it is a robust, efficient method for preparing SDS-containing samples for mass spectrometry. Alternatively, the fractions can be TCA or acetone precipitated and in-solution reduced, alkylated, and digested, but it is critical that the preparation method used removes the SDS from the samples prior to mass spectrometry analysis.

7. Perform LC-MS or MudPIT analysis of the fractions.

If LC-MS analysis will be used, we recommend that the HPLC gradient used for each fraction be at least 90 min long, as most fractions will contain a very large number of peptides from dozens or even hundreds of proteins. 


\section{REAGENTS AND SOLUTIONS}

Use filter-sterilized glass-distilled water or Milli-Q water in all recipes and protocol steps.

20x Protease inhibitor solution-Dissolve one Complete Mini Tablet (Roche, cat. no. $11836153001)$ in $0.5 \mathrm{~mL} \mathrm{dH} \mathrm{H}_{2} \mathrm{O}$. This solution can be stored frozen at $-20^{\circ} \mathrm{C}$ and reused for 3 months.

$200 \mathrm{mM} \mathrm{Na}_{3} \mathrm{VO}_{4}$-Dissolve sodium orthovanadate to a final concentration of $200 \mathrm{mM}$ in sterile $\mathrm{dH}_{2} \mathrm{O}$. Adjust the $\mathrm{pH}$ to 10 and then boil the solution until it turns translucent. Cool the solution and readjust the $\mathrm{pH}$ to 10 . Aliquot the solution and store frozen at $-20^{\circ} \mathrm{C}$.

(Gordon, Methods Enzymol. 1991;201:477-82.)

\section{4x Phosphatase inhibitor solution}

40 mM Sodium Pyrophosphate

$200 \mathrm{mM} \mathrm{NaF}$

$0.4 \mathrm{mM} \mathrm{Na}_{3} \mathrm{VO}_{4}$

The sodium orthovanadate should be diluted from the $200 \mathrm{mM}$ stock solution prepared as described above. The final solution should be aliquoted and stored at $-20^{\circ} \mathrm{C}$.

\section{0x TNC (Tris, $\mathrm{NaCl}, \mathrm{CaCl}_{2}$ ) buffer}

$500 \mathrm{mM}$ Tris- $\mathrm{HCl}(\mathrm{pH} 8.0)$

$500 \mathrm{mM} \mathrm{NaCl}$

$100 \mathrm{mM} \mathrm{CaCl}_{2}$

This solution should be aliquoted and stored at $-20^{\circ} \mathrm{C}$ for long-term use. We find that this and other Tris-based buffers are labile over time, and should not be used for more than 1 month after thawing.

Pronase stock solution-Weigh out a desired amount of Pronase (Roche cat. no. 10165921001 ) and dissolve it in $\mathrm{dH}_{2} \mathrm{O}$ to a final concentration of $10 \mathrm{mg} / \mathrm{mL}$. Prepare a desired number of aliquots, each of $20-50 \mu \mathrm{L}$, and store at $-20^{\circ} \mathrm{C}$. Use a new aliquot for each DARTS experiment.

\section{TE Buffer}

$10 \mathrm{mM}$ Tris-HCl, $\mathrm{pH} 8.0$

$1 \mathrm{mM}$ EDTA

Thermolysin stock solution-Weigh out a desired amount of thermolysin (Sigma cat. no. P1512) and dissolve it in $1 X$ TNC Buffer at a final concentration of $10 \mathrm{mg} / \mathrm{mL}$. Prepare aliquots just as for Pronase and use a new aliquot for each experiment.

\section{2x Triton X-100 lysis buffer}

$0.4 \%$ Triton $\mathrm{X}-100$

$400 \mathrm{mM} \mathrm{NaCl}$

$100 \mathrm{mM}$ Tris- $\mathrm{HCl}(\mathrm{pH} 7.5)$

$20 \%$ Glycerol 


\section{COMMENTARY}

Background Information-DARTS was developed as an alternative to the other common affinity-based target identification methods that necessitate modification of the small molecule (reviewed in (Lomenick et al., 2011)). Its primary advantage over these methods is that the native, unmodified small molecule is used, thereby allowing target identification studies without medicinal chemistry (Lomenick et al., 2009). A detailed review of the development of DARTS, the theory on how it works, and comparison to other target ID methods was recently published and will not be discussed here (Lomenick et al., 2011).

\section{Critical Parameters and Troubleshooting}

Preparation of protein lysates: The exact lysis buffer and method used to extract proteins for use with DARTS is unlikely to be critical. In most cases, however, it should not be overly harsh so that the proteins remain in their "native" (binding-competent) state. In general, (1) proteins should be kept cold, (2) lysis buffers should include protease and phosphatase inhibitors, and (3) mixing should be gentle (proteins and detergents should not be vortexed!). The temperature is kept cold and protease and phosphatase inhibitors are included to prevent any premature degradation and other alterations from occurring to the proteins before the DARTS experiment is performed. The sample is warmed to room temperature just before compound addition and maintained during the proteolysis to help prevent precipitation of the small molecule and to facilitate binding and enzyme activity. Although many small molecules will be completely soluble and even capable of binding their target proteins at $4{ }^{\circ} \mathrm{C}$, others are poorly soluble in aqueous solution and may need fairly high concentrations to reach saturation binding of their targets. Increasing the temperature to a physiological $30^{\circ} \mathrm{C}$ or $37^{\circ} \mathrm{C}$ could also be done to help increase solubility and binding.

An exception to the no vortexing rule is during the bead beating procedure used to lyse yeast or bacterial cells. This procedure has been compatible with DARTS for the proteins we have looked at to date, but alternative lysis buffers for yeast and bacteria that do not require a harsh vortexing step (such as Pierce's Y-PER and B-PER) could be used if necessary.

Small molecule treatment: In most cases, compounds are added directly to the protein lysates of untreated cells. We generally prefer this "in vitro" DARTS approach in order to prevent any small molecule-induced changes in protein levels (expression or turnover), posttranslational modifications (such as those that may signal to the proteasome, aggresome, or caspases and other endogenous proteases), etc. that may occur during the cellular response to the compound. Such changes would not be solely caused by the compound binding to its target protein and may confound the DARTS assay. On the other hand, identification of such changes may still provide valuable information about the compound's cellular mechanism of action.

At least in the cases of didemnin B, rapamycin, and SMER3, the cells could also be treated with the compounds (without re-addition of the compounds during or after cell lysis) and protection of the target proteins was equally as effective as when the compounds were added directly to cell lysates of untreated cells (Lomenick et al., 2009). For some weaker binding compounds, however, it may be worthwhile adding the small molecule to both the cells and into the lysate to help ensure saturation binding of the target proteins. Another potential advantage of in situ compound treatment would be to identify target proteins of metabolites of the small molecule. Some compounds may require chemical modifications inside the cell for their biological activity, and such metabolism of the parent molecules may not occur in the cell lysates. 
Proteolysis: Despite the presence of protease inhibitors in the lysate, which are there solely to prevent the activity of endogenous proteases, the amount of exogenous proteases added into the samples for DARTS is in large excess and overcomes inhibition by the protease inhibitors. At this point in the experiment, even if the in vivo proteases become re-activated (due to potential competitive binding for the protease inhibitors by the DARTS Pronase), it should not confound the DARTS assay because the small molecules are already present to protect the target proteins from proteolysis. Whether the proteolysis occurs via Pronase or endogenous proteases is not critical even though the majority of protease activity in the sample is due to the exogenous protease. The purpose of the protease inhibitors is to prevent degradation of the proteins during or after cell lysis but before the compounds are added to the lysates. If the target proteins were to become degraded before compound addition, then DARTS would never work.

During the proteolysis it is critical that each sample is treated exactly the same to ensure that the amount and time of proteolysis is identical. This is facilitated in our protocol by ensuring that every sample being compared has the same total volume, concentration of protein, salts and other buffer components, and same concentration of DMSO or other solvent. All samples, including the protease, should be thoroughly mixed just before pipetting.

Furthermore the amount of protease added and time of proteolysis for each sample must be identical. This is normally accomplished by spacing the proteolysis of individual samples in 1-min intervals. Alternatively, it should be possible to proteolyse many samples simultaneously using a multi-channel pipette (or higher throughput equipment) in 96-well format.

Analysis of Results: Regardless of the method used to analyze the DARTS results, it is essential to verify that proteolysis of the compound-treated and control samples was comparable. When Western blotting is used, at least one, but preferably multiple, control proteins should be blotted for to show that their digestion is identical. Traditional loading control proteins like tubulin, actin, and GAPDH can be used (except when a "control" itself is targeted by the small molecule of interest, of course), but it is not necessary to be limited to these "housekeeping" proteins. Better controls may include proteins from similar protein families or with similar protease sensitivities to the target proteins. The best control proteins will depend on the amount of protease used. When very high amounts of protease are used, such as Pronase to protein ratios of 1:100 to 1:1000, more stable, protease-resistant proteins such as GAPDH, Hsp90, and pyruvate kinase can be used as digestion controls. When lower amounts of protease are used, such as Pronase to protein ratios of less than 1:1000, these stable proteins will not be digested much or at all, and therefore can only serve as loading controls. Actin, tubulin, and elongation factor-1A are less protease-resistant and can usually serve as digestion controls at this range.

In addition to blotting for control proteins, digestion levels can be estimated by staining the membrane with Ponceau S or SYPRO Ruby protein blot stains (staining will not interfere with, and therefore can also be performed prior to, Western blotting). The majority of bands should look identical between samples digested with the same amount of protease. There should also be a clear difference compared to the non-digested control samples, with either less overall protein present in the digested samples or possibly less protein in the higher molecular weight bands and slightly increased amounts of protein at low molecular weights corresponding to partially digested protein fragments. If any proteomics method besides Western blotting will be used, whether it is gel-based or gel-free, it should be sufficiently quantitative such that the target proteins can be distinguished as enriched versus the majority of non-target proteins that should be present in equal quantities in the samples (Lomenick et al., 2011). 
Anticipated Results-Basic Protocol 1 will result in a range of proteolysis by Pronase within which most proteins will be partially digested at lower Pronase amounts, and completely digested at higher Pronase amounts (see Fig. 3 for example results). Basic Protocol 2 will likewise result in a range of proteolysis by thermolysin under which many proteins will be partially to completely digested. However, some proteins are insensitive to thermolysin and will not be digested even with very high amounts of the protease. These proteins, such as GAPDH, can serve as loading controls for Western blotting. To determine if small molecules bind these proteins, Pronase or other proteases must be used. The magnitude of protection of a compound's target protein from proteolysis varies. We have observed anywhere from a two-fold to a 20 -fold enrichment of a target protein after proteolysis, but a three to five-fold enrichment is most common.

Time Considerations-Once all the reagents are prepared and aliquoted, a single DARTS experiment from preparation of protein lysates to stopping the proteolysis will usually take three to four hours. Additional compounds, doses of compounds, or protein lysates could be included into a single experiment, which would add anywhere from a few minutes to a couple hours to the procedure for an experienced investigator. The time necessary for the remaining analysis, whether it be by SDS-PAGE, Western blotting, or alternative proteomics techniques, will require a few hours to several days, depending on which method is chosen and the exact protocols used.

\section{Acknowledgments}

NIH-funded author? Yes

We thank Simon Diep and Melody Pai for critical reading of the manuscript, the reviewing editor Gregory Weiss for insightful comments, and our colleagues around the world for their interest and helpful discussions. DARTS has been developed with funding support from the National Institutes of Health (R01 CA124974 and R21 CA149774) and the American Cancer Society (RSG-07-035-01-CCG). B.L. was a trainee of the National Institutes of Health UCLA Chemistry-Biology Interface Predoctoral Training Program (T32 GM008496).

\section{Literature Cited}

Aghajan M, Jonai N, Flick K, Fu F, Luo M, Cai X, Ouni I, Pierce N, Tang X, Lomenick B, Damoiseaux R, Hao R, Del Moral PM, Verma R, Li Y, Li C, Houk KN, Jung ME, Zheng N, Huang L, Deshaies RJ, Kaiser P, Huang J. Chemical genetics screen for enhancers of rapamycin identifies a specific inhibitor of an SCF family E3 ubiquitin ligase. Nat Biotechnol. 2010; 28:738-42. [PubMed: 20581845]

Arnold U, Rucknagel KP, Schierhorn A, Ulbrich-Hofmann R. Thermal unfolding and proteolytic susceptibility of ribonuclease A. Eur J Biochem. 1996; 237:862-9. [PubMed: 8647135]

Chen T, Ozel D, Qiao Y, Harbinski F, Chen L, Denoyelle S, He X, Zvereva N, Supko JG, Chorev M, Halperin JA, Aktas BH. Chemical genetics identify eIF2alpha kinase heme-regulated inhibitor as an anticancer target. Nat Chem Biol. 2011; 7:610-6. [PubMed: 21765405]

Ghaemmaghami S, Huh WK, Bower K, Howson RW, Belle A, Dephoure N, O'Shea EK, Weissman JS. Global analysis of protein expression in yeast. Nature. 2003; 425:737-41. [PubMed: 14562106]

Lomenick B, Hao R, Jonai N, Chin RM, Aghajan M, Warburton S, Wang J, Wu RP, Gomez F, Loo JA, Wohlschlegel JA, Vondriska TM, Pelletier J, Herschman HR, Clardy J, Clarke CF, Huang J. Target identification using drug affinity responsive target stability (DARTS). Proc Natl Acad Sci U S A. 2009; 106:21984-9. [PubMed: 19995983]

Lomenick B, Olsen RW, Huang J. Identification of direct protein targets of small molecules. ACS Chem Biol. 2011; 6:34-46. [PubMed: 21077692]

Martzen MR, McCraith SM, Spinelli SL, Torres FM, Fields S, Grayhack EJ, Phizicky EM. A biochemical genomics approach for identifying genes by the activity of their products. Science. 1999; 286:1153-5. [PubMed: 10550052] 
Ross-Macdonald P, Coelho PS, Roemer T, Agarwal S, Kumar A, Jansen R, Cheung KH, Sheehan A, Symoniatis D, Umansky L, Heidtman M, Nelson FK, Iwasaki H, Hager K, Gerstein M, Miller P, Roeder GS, Snyder M. Large-scale analysis of the yeast genome by transposon tagging and gene disruption. Nature. 1999; 402:413-8. [PubMed: 10586881]

Washburn MP, Wolters D, Yates JR 3rd . Large-scale analysis of the yeast proteome by multidimensional protein identification technology. Nat Biotechnol. 2001; 19:242-7. [PubMed: 11231557]

Wisniewski JR, Zougman A, Nagaraj N, Mann M. Universal sample preparation method for proteome analysis. Nat Methods. 2009; 6:359-62. [PubMed: 19377485]

Wolters DA, Washburn MP, Yates JR 3rd . An automated multidimensional protein identification technology for shotgun proteomics. Anal Chem. 2001; 73:5683-90. [PubMed: 11774908]

Zhu H, Bilgin M, Bangham R, Hall D, Casamayor A, Bertone P, Lan N, Jansen R, Bidlingmaier S, Houfek T, Mitchell T, Miller P, Dean RA, Gerstein M, Snyder M. Global analysis of protein activities using proteome chips. Science. 2001; 293:2101-5. [PubMed: 11474067] 


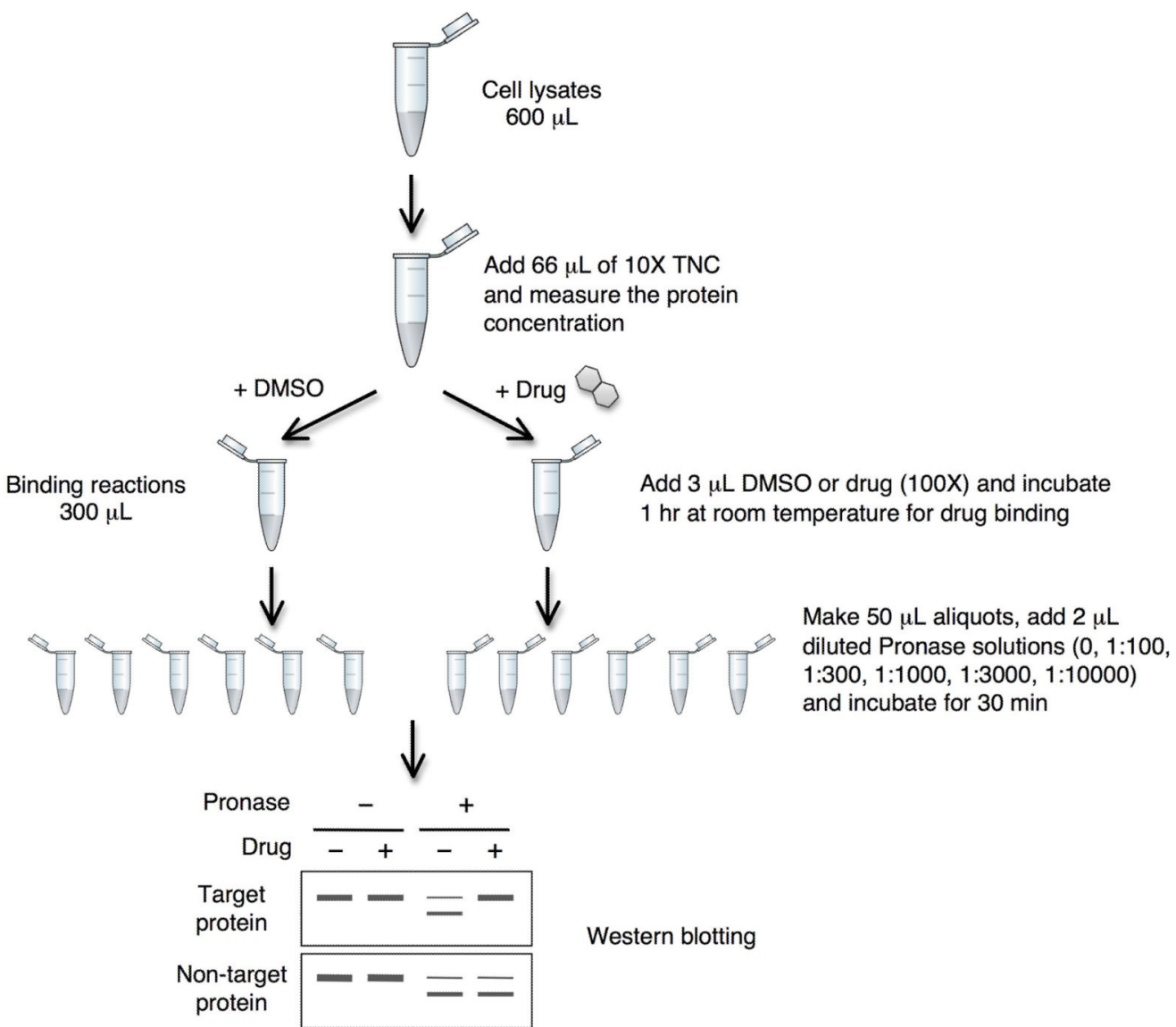

Figure 1. Experimental scheme of DARTS using mammalian cell lysate 


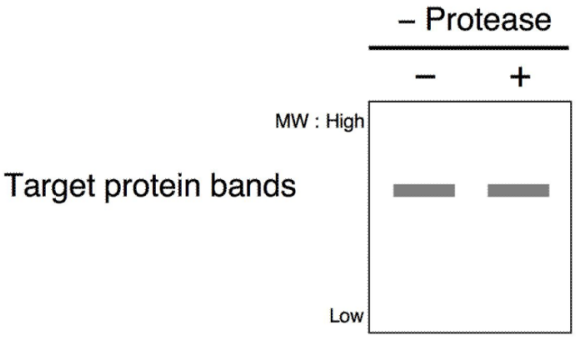

Total amount of target protein

\section{Gel-free fractionation}
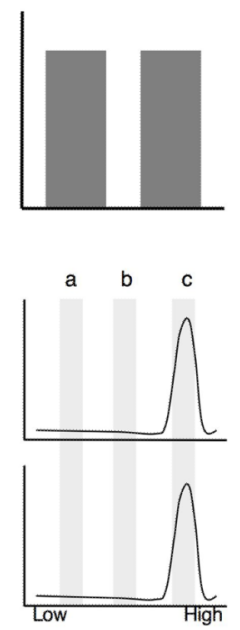

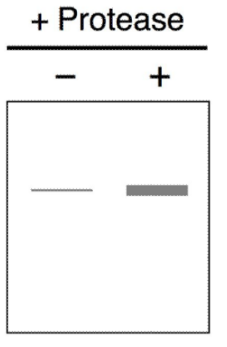

Scenario A
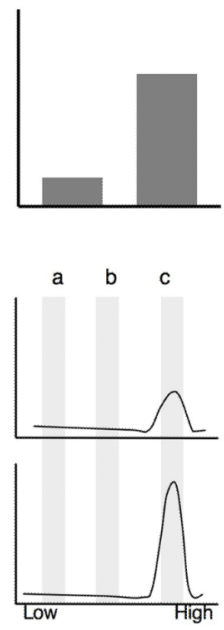
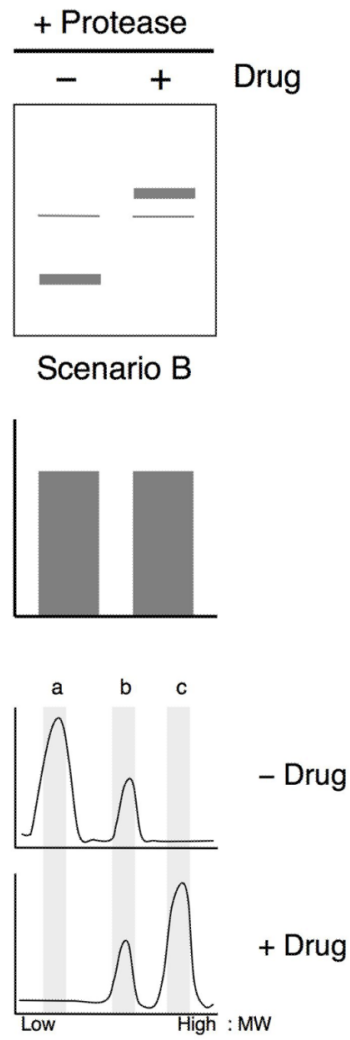

Figure 2. DARTS target identification by Gelfree fractionation vs. whole-sample shotgun MS The starting amount of target protein is equivalent in aliquots of lysate containing and lacking the small molecule. Compound binding causes differential proteolysis of the target protein in DARTS. In Scenario A, the target protein is nearly completely digested in the absence of compound, whereas most of the target protein is undigested in the presence of compound. Both Gelfree fractionation and whole sample shotgun MS analysis are able to identify the target protein here due to its depletion from the control sample. In Scenario B, however, the target protein is only partially digested in the control sample. Here the total amount of target protein is not significantly different between the compound-treated and control samples despite clear protection from proteolysis by the compound. While whole sample shotgun MS is unable to identify the target protein in this case, the Gelfree fractionation approach that takes molecular weight into consideration can identify the target protein based upon its differently-sized fragments in the two samples. 


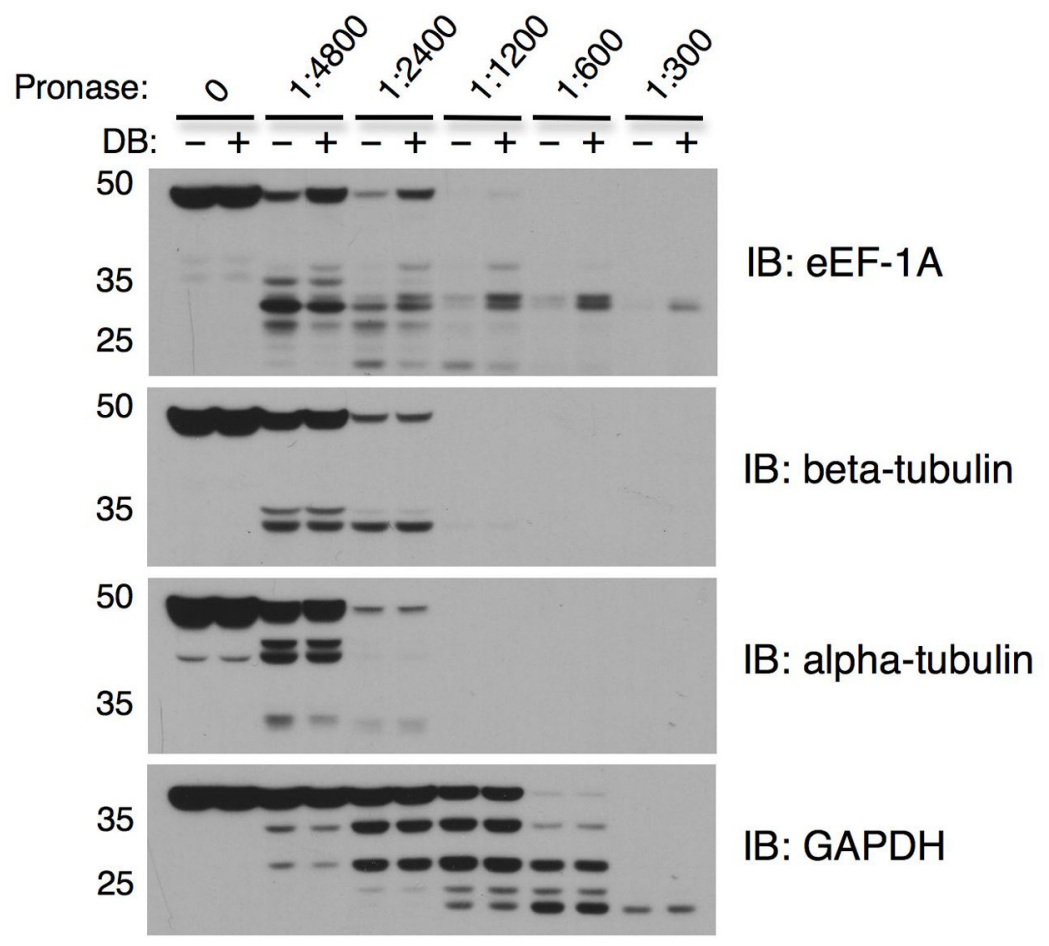

Figure 3. Representative DARTS results for Pronase-digested Jurkat cell lysates Jurkat cell lysates $(6.2 \mu \mathrm{g} / \mu \mathrm{L})$ were prepared as described in Basic Protocol 1, incubated with $10 \mu \mathrm{M}$ didemnin B or DMSO for $1 \mathrm{hr}$, followed by digestion with Pronase to protein ratios of 1:4800, 1:2400, 1:1200, 1:600, and 1:300 for $30 \mathrm{~min}$. Western blotting shows protection of the known target protein eEF-1A, whereas digestion of the non-target proteins GAPDH, alpha-tubulin, and beta-tubulin is unchanged by didemnin B. Notice that GAPDH is more resistant to proteolysis than the other three proteins, requiring a higher Pronase to protein ratio for digestion. 